\title{
Direct oral anticoagulants after stroke: are our patients correctly treated?
}

Bosque-Varela P; Vázquez-Higuera JL; Revilla-García MA;Palacio-Portilla EJ University Hospital Marques de Valdecilla. Neurology Department. Stroke Unit. Santander (SPAIN).

Introduction: Direct oral anticoagulants (DOACs) are effective drugs in the prevention of stroke in patients with non-valvular atrial fibrillation (NVAF). The correct dosage of these drugs contributes to a reduction in the recurrence of stroke and hemorrhagic complications.

Goals: To assess the percentage of patients receiving the correct dose of DOACs after an ischemic stroke or TIA. To detect factors involved in an incorrect dosage of these drugs.

Method: Retrospective analysis of consecutive patients admitted to our stroke unit during a period of 5 years with a diagnosis of NVAF, and for whom treatment with DOACs was prescribed. Stastistical analysis: t-student, Mann-Whitney U, Chi-square and logistic regression analysis.

\section{Results:}

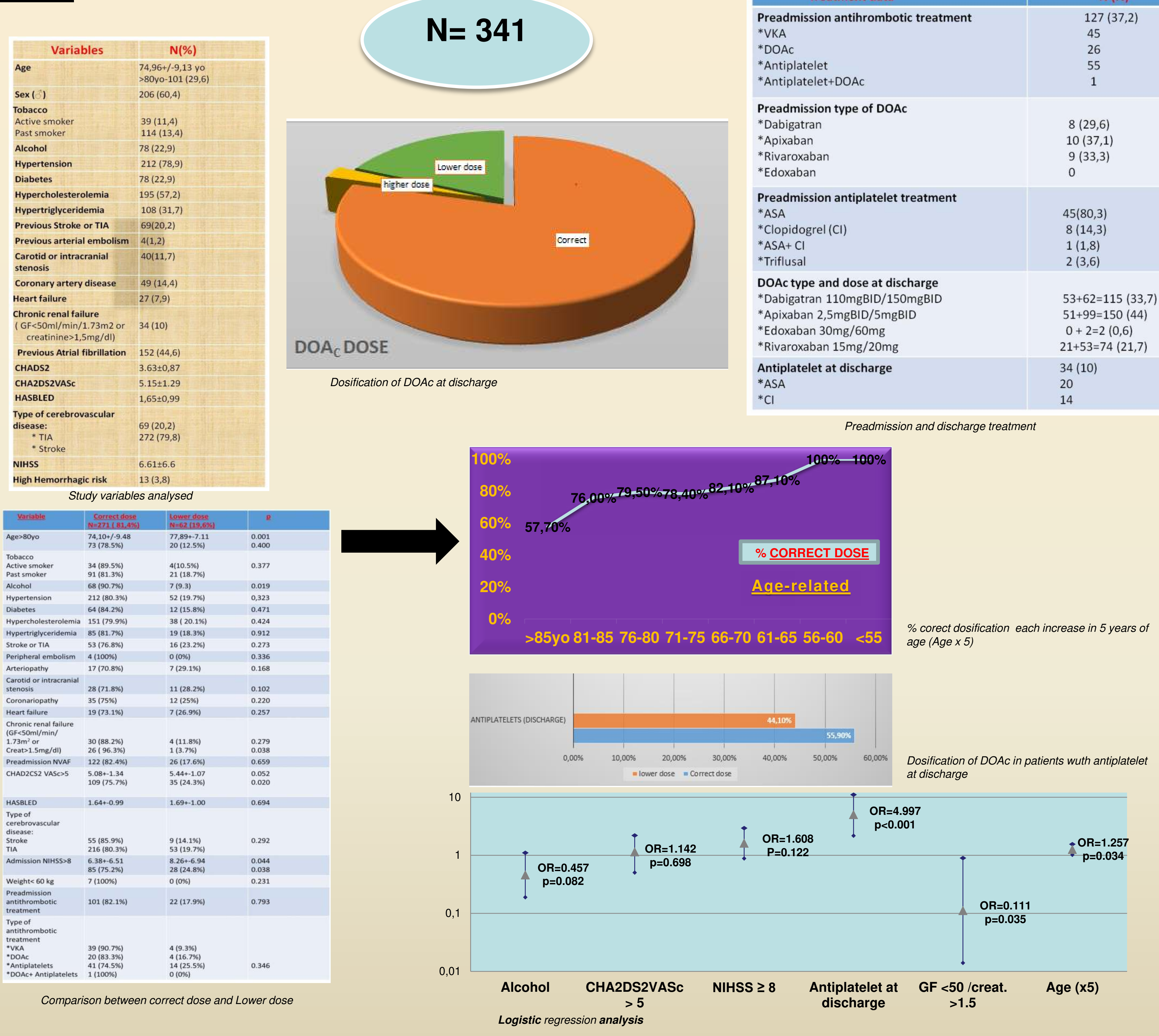

Conclusions:

Approximately $20 \%$ of our patients received an incorrect dose of DOAcs. (Lower dose:18,2\% and higher dose: $2,3 \%$ ).

Each increase in five years of age and the concomitant treatment with antiplatelets were the main factors associated with infradosificacion. Furthermore, patients with GF $<50 \mathrm{ml} / \mathrm{min} / 1.73 \mathrm{~m}^{2}$ or creatinine $>1.5 \mathrm{mg} / \mathrm{dl}$ were usually correctly dosified.

Both lower dose and higher doses could contribute to an increase of recurrence of Stroke and hemorrhagic complications. 